\title{
Conocimiento, innovación y estrategias públicas de desarrollo: análisis comparado de tres ciudades medias de Andalucía (España)
}

Inmaculada Caravaca. Universidad de Sevilla, Sevilla, España.

Gema González. Universidad de Sevilla, Sevilla, España.

Antonio García. Universidad de Pablo de Olavide, Sevilla, España.

Víctor Fernández. Universidad de Sevilla, Sevilla, España.

Aída Mendoza. Universidad de Sevilla, Sevilla, España.

RESUMEN | La inserción de empresas y territorios en un mundo globalizado está condicionada, entre otros factores, por su capacidad para incorporar conocimiento y realizar innovaciones. No es de extrańar, por consiguiente, que dichas capacidades se conviertan en el punto de confluencia de diferentes corrientes epistemológicas y disciplinas científicas que reflexionan acerca de si pueden constituir la base de un nuevo modelo socioeconómico. Junto a lo anterior, emerge una nueva cultura territorial que dedica una atención especial a las ciudades medias, al considerar que pueden inducir efectos multiplicadores sobre su entorno y contrarrestar así los procesos concentradores provocados por las grandes ciudades. El objetivo de este artículo es realizar un análisis comparado de algunas ciudades medias en una región del sur de España, Andalucía, desde varias perspectivas: su grado de inserción en la sociedad del conocimiento, su capacidad innovadora y las redes locales de colaboración que pueden propiciarla, y las estrategias públicas de desarrollo local que en ellas se están implementando.

PALABras ClaVe $\mid$ sociedad del conocimiento, desarrollo urbano, política urbana.

ABSTRACT | The ability to incorporate knowledge and to innovate is conditioning the way firms and territories are engaging in the globalized world. It is therefore not surprising that this should become the focal point for a range of epistemological currents and scientific disciplines that see this as the basis of a new model of socio-economic development. At the same time, a new territorial culture has emerged that focuses on medium-size cities as the key to inducing multiplicative effects on their surrounding areas and halting the concentration effects of large cities. The objective of this article is to carry out a three-pronged comparative analysis of some medium-size towns and cities in Andalusia (Spain): the degree to which they engage in the knowledge society; their ability for innovation and the local collaboration networks that could favor this, and local public development strategies.

KEY WORDS | knowledge society, urban development, urban policy.

Recibido el 11 de junio de 2012, aprobado el 16 de diciembre de 2012

E-mail: Inmaculada Caravaca, caravaca@us.es | Gema González, gemagonzalez@us.es | Antonio García, agargar1@upo.es | Víctor Fernández, salinas@us.es | Aída Mendoza, aidamendoza@us.es

Este artículo se integra en dos Proyectos de Investigación del Plan Nacional Espańol de I+D+i: SEJ 2006-14277-CO04-03, cofinanciado con el Fondo Europeo de Desarrollo Regional (FEDER); y COS2009-10888. 


\section{Introducción}

En el contexto de un sistema económico fuertemente globalizado y competitivo, las empresas y los territorios tienen que desarrollar estrategias para aprovechar las oportunidades que puedan conferirles ventajas, y buscar soluciones para resolver los nuevos problemas a los que deben hacer frente. El territorio se convierte así en "el principal receptor de los efectos de la globalización y en el principal emisor de respuestas a sus retos" (Brugué, Gomá \& Subirats, 2002, p. 19).

En Europa, la menor capacidad competitiva de las regiones consideradas periféricas, relacionada con las estructuras económicas, sociales y territoriales en ellas imperantes, constituye un importante freno para avanzar en los procesos de desarrollo. A este problema estructural hay que añadir ahora los graves efectos producidos por la crisis económica que, como es sabido, está afectando con especial dureza a estos territorios y generando en ellos profundas disfunciones, tanto económicas (reducción del crecimiento, cierre de empresas, hundimiento del mercado inmobiliario, déficit en las cuentas públicas...), como sociales (desempleo, precarización laboral, aumento de la pobreza y la exclusión, emigración...). Ante esta situación, el diseño de estrategias que les permitan suavizar sus deficiencias estructurales y encontrar la forma de superar la crisis se convierte en un importante reto. Para lograrlo, resulta imprescindible profundizar en el conocimiento de los distintos ámbitos territoriales que forman parte de dichas regiones y, muy especialmente, de sus ciudades medias, dada su capacidad -al menos teórica- para actuar como vertebradoras del territorio y contribuir a difundir los procesos de desarrollo (Bellet \& Llop, 2000).

En este contexto general de referencia, el objetivo de este artículo es realizar un análisis comparado de algunas ciudades medias de Andalucía (sur de España), desde varias perspectivas: su grado de inserción en la sociedad del conocimiento, la capacidad innovadora de sus empresas, las redes locales de colaboración socio-institucional y las estrategias públicas locales de desarrollo que se están llevando a cabo.

Para hacer operativo este objetivo, se parte de una serie de preguntas de investigación, tales como:

- ¿Son los indicadores disponibles a escala municipal suficientes y adecuados para analizar el dinamismo económico y la capacidad innovadora?

- ¿Influye la localización y la funcionalidad de las ciudades en la capacidad innovadora de sus empresas?

- ¿Qué papel desempeñan los recursos específicos, los actores (privados y públicos) y las redes locales de colaboración en el dinamismo socioeconómico y la capacidad innovadora de las ciudades?

- ¿Cómo puede ayudar esta investigación a reinterpretar los procesos de desarrollo territorial, ofreciendo nuevas orientaciones a las políticas públicas de promoción económica y de ordenación territorial? 
Con este planteamiento de partida, los datos estadísticos disponibles a escala local no resultan suficientes para profundizar en todos los aspectos que interesan. $\mathrm{Ha}$ sido, pues, necesario complementarlos generando nueva información mediante la realización de trabajo de campo, entre los años 2009 y 2011. Esta circunstancia, junto al hecho de que ya se hayan llevado a cabo análisis cuantitativos de las ciudades andaluzas en distintos proyectos de investigación anteriormente realizados ${ }^{1}$, justifica que este artículo se centre únicamente en tres ciudades, que han sido seleccionadas teniendo en cuenta los resultados obtenidos en dichas investigaciones.

Así, en uno de estos proyectos, y utilizando indicadores tanto de dinamismo socioeconómico como de innovación, se abordaba el análisis de todas las ciudades pequeñas y medias para, aplicando diferentes técnicas estadísticas, proponer una tipología de las que superaban los valores promedios de la región (Caravaca, González, Mendoza \& Silva, 2009). Por su parte, en otra de las investigaciones se estudiaban todas las ciudades andaluzas a partir de técnicas multivariantes, basándose en indicadores de diversa procedencia relacionados con los recursos de conocimiento, las actividades intensivas en $\mathrm{I}+\mathrm{D}$, y los esfuerzos para innovar y sus resultados. Ello permitió establecer correlaciones espaciales y derivar de ellas una tipología de ciudades que evidenciaban sus diferentes vías de acceso a la sociedad del conocimiento (Méndez, Abad, Caravaca \& González, 2010). A los dos proyectos anteriores, centrados ambos en el estudio de las ciudades de Andalucía, hay que añadir algunos otros en los que también se utiliza un número significativo de variables e indicadores que miden el grado de desarrollo territorial de esta región a escala municipal (García, 2008; González, 2009; Pita \& Pedregal, 2011; Zoido, 2001; Zoido \& Caravaca, 2005). Todas estas investigaciones han servido de base para la selección de las ciudades objeto de estudio.

En definitiva, este artículo -que desde el punto de vista teórico incorpora conceptos y reflexiones vinculadas al conocimiento, la innovación y el desarrollo territorial- realiza algunas aportaciones metodológicas al proponer una selección de indicadores aplicables a escala local procedentes de las fuentes estadísticas al uso. A estas anteriores hay que añadir otras aportaciones de carácter empírico, sustentadas en un sistemático trabajo de campo que ha permitido generar información complementaria, tanto de carácter cuantitativo (basada en la realización de encuestas a empresas), como cualitativo (a partir de entrevistas semiestructuradas a empresas e instituciones).

Los proyectos de investigación a los que se alude son de financiación pública y se han aprobado en convocatorias competitivas: Observatorio de la Cohesión y el Desarrollo Territorial de Andalucía (Junta de Andalucía); Las ciudades de Andalucía en la sociedad del conocimiento (Instituto de Estadística de Andalucía); Procesos de innovación en ciudades intermedias y desarrollo territorial policéntrico en Espańa. Las ciudades medias como potencial recurso para el desarrollo de Andalucía (Ministerio de Ciencia y Tecnología, y Fondos FEDER); Las regiones metropolitanas espańolas en la sociedad del conocimiento. Tendencias económicas y transformaciones territoriales (Ministerio de Educación y Ciencia). 


\section{Marco teórico de referencia}

La capacidad de generar e incorporar conocimientos y realizar innovaciones puede entenderse como una de las principales claves del éxito de empresas y territorios, al permitirles encontrar respuestas imaginativas con las que resolver sus problemas y hacer frente a sus disfunciones, con un doble objetivo: insertarse competitivamente en el sistema mundo y mejorar las condiciones de vida de sus habitantes.

No puede extrańar, por lo tanto, que se haya generalizado el uso de las categorías conceptuales de sociedad del conocimiento y economía del conocimiento para hacer referencia a aquellas en las que este ocupa un lugar preeminente (Boisier, 2001; David \& Foray, 2002; Drucker, 1969; Machlup, 1962; Rohrbach, 2007; Unesco, 2005). Aunque estos conceptos se originaron a mediados del siglo $\mathrm{xx}$, es ahora cuando ocupan un lugar destacado no solo en el debate científico, sino incluso en el discurso institucional, al ofrecer "una visión del futuro para guiar normativamente las acciones políticas" (Krüger, 2006, p. 2). Son ya muchos los investigadores interesados en estos contenidos, si bien los abordan desde perspectivas distintas. Mientras algunos enfatizan el protagonismo ejercido por el conocimiento en las relaciones sociales de producción, en la reorganización del poder y en la emergencia del network state (Carnoy \& Castells, 2001), otros se centran en el análisis de su influencia en los comportamientos empresariales, las dinámicas territoriales y el desarrollo (Amin \& Cohendet, 2004; Cooke, 2002; Méndez, 2002; Moulaert \& Nussbaumer, 2005) o la estudian desde la perspectiva de las políticas públicas (Caravaca, García \& González, 2012; Rooney, Hearn, Mandeville \& Joseph, 2003). Algunos de los investigadores revisan, además, estos conceptos con una mirada crítica, contribuyendo así a matizar buena parte de sus interpretaciones (Coe, 2005; Romeiro \& Méndez, 2008).

Junto a lo anterior, la innovación, entendida como aplicación del conocimiento, ha sido también objeto de múltiples reflexiones e investigaciones. Así, al lado de las interpretaciones más tradicionales ligadas al comportamiento de las empresas (Cating, Lacour \& Lung, 2001; Feldman, 1994), se incorporan otras cuyas perspectivas son mucho más abiertas, puesto que consideran que el proceso innovador es más complejo al no tener carácter individual sino colectivo y estar vinculado a las sociedades, las instituciones y los territorios (Albertos, Caravaca, Méndez \& Sánchez, 2004; MacKinnon, Cumbres \& Chapman, 2002; Méndez, 2002; Moulaert \& Sekia, 2003). La innovación, entendida, pues, desde esta doble perspectiva, se convierte también en un importante factor que condiciona no solo el dinamismo económico, sino también el desarrollo territorial.

Pero sea cual sea el punto de vista con el que se utilizan estos conceptos, parece evidente el interés de los argumentos que los sustentan en un contexto de crisis sistémica tan grave como la actual. Por una parte, la capacidad de generar e incorporar conocimientos y realizar innovaciones puede considerarse una de las principales claves del éxito de las empresas. Por otra, estos conocimientos e innovaciones condicionan también los territorios en los que se localizan; y no solo porque se trata de recursos que son difícilmente deslocalizables, sino porque constituyen la base de 
un nuevo modelo económico. Por último, permiten a las instituciones locales encontrar respuestas con las que hacer frente a sus propios problemas y disfunciones.

Desde una perspectiva territorial, parece demostrada la tendencia concentradora del conocimiento y de la innovación en las principales ciudades y aglomeraciones urbanas (Carrillo, 2006; Méndez, Sánchez, Abad \& García, 2009; Romeiro \& Méndez, 2008; Simmie, Sennett, Wood \& Hart, 2002; Winden, Van Berg \& Pol, 2007). No obstante, existen ciudades medias en las que destaca también su presencia, lo que resulta especialmente interesante para propiciar procesos de desarrollo territorial (Caravaca et al., 2009; Méndez, 2009; Méndez, Michelini \& Romeiro, 2006; O’Huallacháin \& Leslie, 2007). En este último sentido, cabe llamar la atención sobre la revalorización experimentada por las ciudades medias, al considerarlas clave para inducir efectos multiplicadores sobre su entorno y contrarrestar así los procesos concentradores directamente responsables de los desequilibrios territoriales (Atkinson, 2001; Balbo, 1997; Bellet \& Llop, 2000; Davoudi, 2003; European Communities, 1999; Gaspar, 2000; Henderson, 1997).

\section{Marco territorial de referencia e indicadores de inserción en la economía del conocimiento}

Andalucía es una región periférica, tanto en el contexto europeo como en el español, y está aquejada de un conjunto de debilidades estructurales que dificultan su desarrollo: insuficiente e inadecuada formación de los recursos humanos, falta de cultura empresarial, baja competitividad; a tales debilidades se suma la especialización en sectores maduros y basados en el uso de recursos genéricos, entre los que destaca la construcción; escasez de determinados servicios empresariales, incapacidad para generar un suficiente número de empleos... Resulta evidente que las instituciones, las empresas y la sociedad en su conjunto necesitan hacer un importante esfuerzo para superar problemas tan graves y complejos. Pero, como contrapunto a lo anterior, Andalucía cuenta con un recurso territorial de especial interés: un sistema urbano muy equilibrado, con una importante red de ciudades medias (entendiendo en este contexto como tales aquellas cuya población oscila entre 20.000 y 250.000 habitantes) que están, además, bien distribuidas por el espacio regional, lo que puede facilitar la difusión del conocimiento y las innovaciones por el conjunto del territorio.

Teniendo en cuenta las investigaciones antes citadas, se han seleccionado tres ciudades medias cuyos indicadores han tenido un comportamiento positivo en los estudios anteriormente mencionados y son, además, muestra de la diversidad existente en Andalucía en otras características, como su tamaño, el ámbito territorial en el que se localizan, su funcionalidad y su base económica. Partiendo de tales planteamientos, los casos seleccionados son los siguientes (Figura 1): 
FIGURA 1 | Red de ciudades medias de Andalucía y localización de las estudiadas

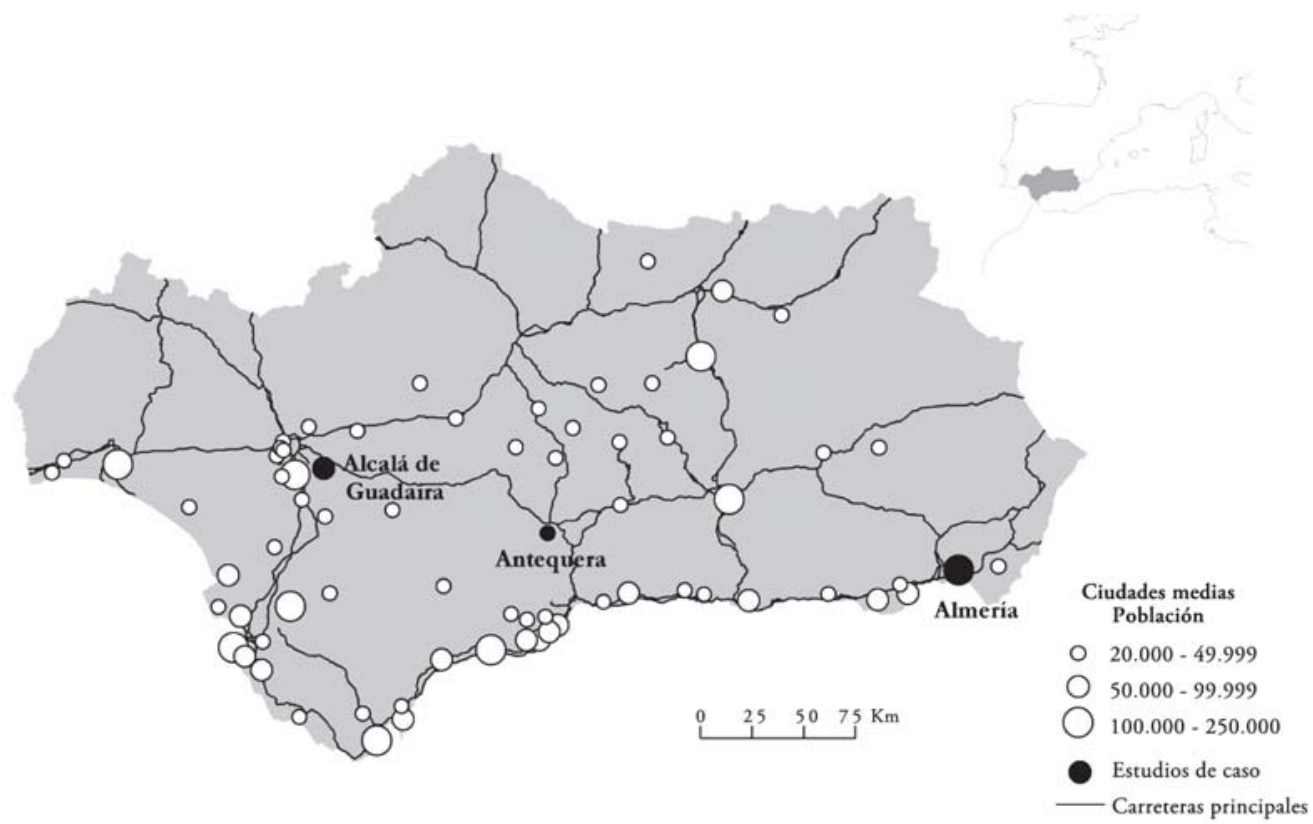

FUENTE ELABORACIÓN PROPIA

- Antequera, ciudad interior de 41.854 habitantes (Instituto de Estadística y Cartografía de Andalucía, 2011), ha estado inmersa en un proceso urbanístico expansivo que hay que poner en relación con su privilegiado emplazamiento en el centro de Andalucía y su situación estratégica respecto a las principales vías de comunicación de la región. Dicha dinámica está provocando una cierta presión y desorden territorial debidos, por una parte, a procesos de urbanización ilegal; $\mathrm{y}$, por otra, a las barreras territoriales que han generado algunas de las nuevas infraestructuras de transporte. Desde la perspectiva económica, su ya mencionada centralidad territorial motiva que se esté apostando por una especialización en actividades de logística y distribución que están transformado su estructura económica tradicional, basada en la existencia de actividades primarias e industriales de primera transformación.

- Alcalá de Guadaíra, con 72.800 habitantes (Instituto de Estadística y Cartografía de Andalucía, 2011), forma parte de la primera corona del área metropolitana de Sevilla, habiendo experimentado durante los últimos ańos un fuerte crecimiento poblacional y urbanístico. Al contrario de lo que ocurre en la mayor parte de la aglomeración, esta ciudad se caracteriza por una destacada presencia de la industria, que resulta significativa también en el contexto regional. Este hecho ha condicionado tanto su modelo económico como su comportamiento territorial, al concentrarse en este municipio una buena parte del suelo empresarial de la aglomeración urbana de Sevilla. 
- Almería, cuya población asciende a 190.349 habitantes (Instituto de Estadística y Cartografía de Andalucía, 2011), se localiza en el litoral y es capital administrativa de la provincia del mismo nombre. Hasta hace pocos decenios, esta provincia era una de las menos desarrolladas de España; sin embargo, ha experimentado un significativo crecimiento económico basado en el turismo y, sobre todo, en la agricultura intensiva de invernadero. Los requerimientos de esta agricultura y el empuje, hasta ahora creciente, de la comercialización hortofrutícola han propiciado un proceso de articulación empresarial que ha conformado un complejo sistema productivo. En él es significativa la presencia de industrias biotecnológicas y de una intensa actividad investigadora tanto pública como privada. La ciudad de Almería, pese a su condición de capital provincial y la evolución positiva de buena parte de los indicadores vinculados con la sociedad del conocimiento, se está quedando algo rezagada respecto a otras ciudades de su entorno más próximo, que compiten con ella en la atracción de servicios, equipamientos y sedes sociales de algunas empresas. Ciertas deficiencias infraestructurales y una actitud social poco activa pueden ayudar a entender la existencia de una crisis de capitalidad que está provocando un desplazamiento del centro de gravedad no solo económico, sino también sociodemográfico, a otros municipios de su provincia.

Una vez expuesto el contexto territorial y las ciudades seleccionadas, resulta imprescindible hacer referencia a los indicadores utilizados. Teniendo en cuenta la creciente importancia del conocimiento y la innovación como posibles impulsores del desarrollo, son diversos los estudios que han buscado indicadores relacionados con la formación del capital humano, la presencia de actividades intensivas en conocimiento, el esfuerzo innovador realizado por las empresas o los resultados obtenidos con tal esfuerzo (Arboníes, 2005; European Commission, 2005, 2006; Fernández \& González, 2009). Especial interés para este artículo tienen los análisis realizados en España sobre los indicadores disponibles a escala municipal (Caravaca, González \& Mendoza, 2007; González, 2006; Méndez et al., 2009; Méndez et al., 2010). Teniéndolos muy en cuenta, se ha recogido la información más completa y actualizada posible para las tres ciudades objeto de estudio ${ }^{2}$.

Tal y como ya se ha señalado, en España existen graves deficiencias de información a escala local, por lo que ha sido necesario recopilar fuentes muy diversas para llevar a cabo este análisis. De este modo, los datos utilizados proceden de diversos organismos que los recogen y ordenan con muy diferentes objetivos y criterios: Instituto Nacional de Estadística, Instituto de Estadística y Cartografía de Andalucía, Asociación Española de Normalización y Certificación, Instituto de Comercio Exterior, Centro de Desarrollo Tecnológico e Industrial; Consejería de Innovación, Ciencia y Empresa de la Junta de Andalucía; Oficina Española de Patentes y Marcas; y Telefónica.

Los datos censales de 2011 aún no están publicados, siendo los disponibles los de 2001, lo que demuestra las deficiencias de la información territorializada en España. 
Un primer grupo de indicadores está relacionado con los recursos para el conocimiento y la innovación, al entender que son fundamentales para la competitividad y el desarrollo de los territorios. Tal y como han señalado algunos autores, "aquellas ciudades capaces de asegurar una alta tasa de producción de ese conocimiento (científico, técnico, simbólico, procedimental o compartimental), junto a una amplia circulación interna y una aplicación práctica (a la actividad de sus empresas, la gestión pública y de las organizaciones locales, etcétera), estarán en mejores condiciones para avanzar por el camino de la innovación y el desarrollo" (Méndez et al., 2009, p. 120).

Se incluye en este grupo un recurso tan básico como la población con mayor nivel de conocimientos y, en consecuencia, mejor preparada para realizar innovaciones, así como su peso en el mercado de trabajo. Como recoge el Cuadro 1, estos efectivos no destacan en las ciudades objeto de estudio ni por su peso ni por su evolución; no obstante, si se relaciona el porcentaje de contratos registrados de estos colectivos respecto al total con su participación en el conjunto de la población de más de dieciséis años (B-A), los valores obtenidos son más positivos que los del resto de las ciudades andaluzas, especialmente en Alcalá de Guadaíra. Esto demuestra que en estas ciudades, independientemente de sus diferencias estructurales y de localización, el mercado de trabajo tiene una mayor capacidad de absorción de la población más cualificada que en otras de la región.

\section{CUADRO 1 Indicadores de recursos e infraestructuras para la innovación}

\begin{tabular}{|c|c|c|c|c|c|}
\hline & ANTEQUERA & $\begin{array}{l}\text { ALCALÁ DE } \\
\text { GUADAÍRA }\end{array}$ & ALMERÍA & $\begin{array}{l}\text { CIUDADES } \\
\text { MEDIAS DE } \\
\text { ANDALUCÍA }\end{array}$ & $\begin{array}{c}\text { TOTAL } \\
\text { CIUDADES DE } \\
\text { ANDALUCÍA }\end{array}$ \\
\hline $\begin{array}{l}\text { Población estudios universitarios/ } \\
\text { población > } 16 \text { años (\%), } 2001 \text { (A) }\end{array}$ & 6,89 & 5,97 & 11,70 & 10,88 & 19,09 \\
\hline $\begin{array}{l}\text { Evolución de la población con } \\
\text { estudios universitarios, } \\
\text { 1991-2001 }(1991=100)\end{array}$ & 180,52 & 279,34 & 193,87 & 203,87 & 199,08 \\
\hline $\begin{array}{l}\text { Contratos registrados de } \\
\text { trabajadores con estudios } \\
\text { universitarios/contratos } \\
\text { totales (\%), } 2008 \text { (B) }\end{array}$ & 5,20 & 7,65 & 11,53 & 8,57 & 9,30 \\
\hline B-A & $-1,69$ & $+1,68$ & $-0,17$ & $-2,31$ & $-9,79$ \\
\hline $\begin{array}{l}\text { Centros de generación, } \\
\text { aplicación y transferencia de } \\
\text { conocimiento, } 2009\end{array}$ & & & 3 & 56 & 123 \\
\hline Parques tecnológicos, 2009 & & & 1 & 6 & 13 \\
\hline $\begin{array}{l}\text { Líneas RDSI + ADSL/habitantes (\%), } \\
2008\end{array}$ & 12,38 & 12,30 & 12,43 & 12,66 & 12,94 \\
\hline $\begin{array}{l}\text { Evolución líneas RDSI + ADSL (\%), } \\
\text { 2003-2008 }\end{array}$ & 69,32 & 63,19 & 58,04 & 60,78 & 61,68 \\
\hline
\end{tabular}

FUENTES INSTITUTO NACIONAL DE ESTADÍSTICA, INSTITUTO DE ESTADÍSTICA Y CARTOGRAFÍA DE ANDALUCÍA; CONSEJERÍA DE INNOVACIÓN, CIENCIA Y EMPRESA-JUNTA DE ANDALUCÍA; TELEFÓNICA 
Por su parte, pueden considerarse también como recursos las infraestructuras al servicio de la innovación, entre las que se incluyen los centros de generación, aplicación y transferencia de conocimientos, así como los parques tecnológicos; tanto unos como otros tienden a concentrarse en las ciudades de mayor tamańo, por lo que Almería destaca entre las tres analizadas. Por el contrario, en cuanto a la dotación o evolución de las líneas rdsi + adsl, infraestructuras imprescindibles en la sociedad del conocimiento, no se observan diferencias significativas entre las tres ciudades objeto de estudio y el conjunto de las andaluzas.

El segundo grupo de indicadores utilizados incluye el número de establecimientos empresariales especializados en actividades propias de la economía del conocimiento, considerando como tales las actividades identificadas en la propuesta realizada por la Organización para la Cooperación y el Desarrollo Económico (ocDE, 2001) ${ }^{3}$. Según muestra el Cuadro 2, existen marcados contrastes entre las ciudades estudiadas y entre estas y las restantes, destacando Alcalá de Guadaíra y Almería con una mayor presencia de estas actividades.

\section{CUADRO 2 Establecimientos empresariales de sectores creativos e intensivos en conocimiento, 2008}

\begin{tabular}{|l|c|r|r|r|c|}
\cline { 2 - 6 } & ANTEQUERA & $\begin{array}{c}\text { ALCALÁ } \\
\text { DE } \\
\text { GUADAÍrA }\end{array}$ & ALMERÍA & $\begin{array}{c}\text { PROMEDIO } \\
\text { CIUDADES } \\
\text { MEDIAS DE } \\
\text { ANDALUCía }\end{array}$ & $\begin{array}{c}\text { PROMEDIO } \\
\text { TODAS LAS } \\
\text { CIUDADES DE } \\
\text { ANDALUCía }\end{array}$ \\
\hline $\begin{array}{l}\text { Industrias alta intensidad } \\
\text { tecnológica }\end{array}$ & 10 & 49 & 82 & 26 & 24 \\
\hline $\begin{array}{l}\text { Industrias culturales y servicios } \\
\text { creativos }\end{array}$ & 80 & 168 & 433 & 129 & 119 \\
\hline $\begin{array}{l}\text { Servicios basados en conocimiento } \\
\text { Total establecimientos creativos e } \\
\text { intensivos en conocimiento }\end{array}$ & 666 & 931 & 4.617 & 985 & 949 \\
\hline $\begin{array}{l}\text { Establecimientos creativos e } \\
\text { intensivos en conocimiento / } \\
\text { total establecimientos }\end{array}$ & 0,24 & 0,21 & 0,35 & 0,27 & 0,29 \\
\hline
\end{tabular}

FUENTE INSTITUTO DE ESTADÍSTICA Y CARTOGRAFÍA DE ANDALUCÍA

Para el análisis del esfuerzo innovador realizado por las empresas, resulta útil considerar el número de proyectos que han recibido financiación pública, la inversión movilizada con ellos, las ayudas o incentivos recibidos, así como las estrategias de

3 Según la ocDE, los sectores creativos e intensivos en conocimiento son:

- Industrias de alta intensidad tecnológica: química; fabricación de máquinas de oficina y equipos informáticos; fabricación de material electrónico y equipos y aparatos de radio, televisión y comunicaciones; fabricación de equipo e instrumentos médico-quirúrgicos, de precisión, óptica y relojería; y fabricación de otro material de transporte.

- Industrias culturales y de servicios creativos: edición, artes gráficas y reproducción de soportes grabados y actividades recreativas, culturales y deportivas.

- Servicios basados en conocimiento: correos y telecomunicaciones, intermediación financiera, seguros y planes de pensiones, actividades auxiliares a la intermediación financiera; actividades informáticas, investigación y desarrollo; educación, y actividades sanitarias, veterinarias y de servicio social. 
diferenciación basadas en la apuesta por la calidad. El Cuadro 3 vuelve a evidenciar cómo Alcalá de Guadaíra y Almería han realizado un esfuerzo innovador que las distingue en el conjunto de las ciudades andaluzas, mientras Antequera se muestra mucho menos dinámica en este aspecto.

CUADRO 3 | Esfuerzo innovador

\begin{tabular}{|c|c|c|c|c|c|}
\hline & ANTEQUERA & $\begin{array}{r}\text { ALCALÁ DE } \\
\text { GUADAÍrA }\end{array}$ & ALMERÍA & $\begin{array}{l}\text { PROMEDIO } \\
\text { CIUDADES } \\
\text { MEDIAS DE } \\
\text { ANDALUCÍA }\end{array}$ & $\begin{array}{c}\text { PROMEDIO } \\
\text { TODAS LAS } \\
\text { CIUDADES DE } \\
\text { ANDALUCÍA }\end{array}$ \\
\hline \multicolumn{6}{|c|}{ Proyectos de I+D+i financiados por el Centro de Desarrollo Tecnológico e Industrial (2000-2008) } \\
\hline No proyectos & 4 & 5 & 9 & 3 & 2 \\
\hline $\begin{array}{l}\text { Inversión realizada } \\
\text { (miles €) }\end{array}$ & $2.116,00$ & $5.849,91$ & $4.460,10$ & $2.311,65$ & $2.163,70$ \\
\hline $\begin{array}{l}\text { Subvenciones recibidas } \\
\text { (miles } € \text { ) }\end{array}$ & $1.304,14$ & $2.496,28$ & $2.093,01$ & $1.092,96$ & $1.011,64$ \\
\hline \multicolumn{6}{|c|}{ Proyectos de I+D+i incentivados por la Consejería de Innovación, Ciencia y Empresa (2005-2008) } \\
\hline No proyectos & - & 14 & 21 & 3 & 6 \\
\hline $\begin{array}{l}\text { Incentivos recibidos } \\
\text { (miles } € \text { ) }\end{array}$ & - & $1.076,99$ & $1.617,30$ & 409,52 & 974,39 \\
\hline \multicolumn{6}{|c|}{ Certificaciones de Calidad concedidas por la Asociación Española de Normalización y Certificación (2008) } \\
\hline No certificaciones & 50 & 154 & 292 & 58 & 61 \\
\hline
\end{tabular}

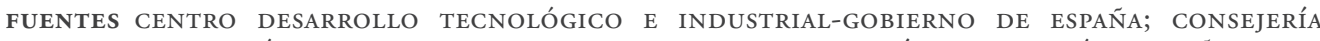
INNOVACIÓN, CIENCIA Y EMPRESA-JUNTA DE ANDALUCÍA; ASOCIACIÓN ESPAÑOLA DE NORMALIZACIÓN Y CERTIFICACIÓN

Por último, los resultados de la innovación pueden cuantificarse a partir del número de patentes registradas y de la capacidad de las empresas para insertarse en mercados externos. Nuevamente, Alcalá de Guadaíra y Almería destacan significativamente en relación con Antequera, pero también respecto al resto de las ciudades (Cuadro 4).

CUADRo 4 | Resultados de la innovación

\begin{tabular}{|l|c|c|c|c|c|}
\cline { 2 - 6 } & ANTEQUERA & $\begin{array}{c}\text { ALCALÁ DE } \\
\text { GUADAÍrA }\end{array}$ & ALMERÍA & $\begin{array}{c}\text { PROMEDIO } \\
\text { CIUDADES } \\
\text { MEDIAS DE } \\
\text { ANDALUCía }\end{array}$ & $\begin{array}{c}\text { PROMEDIO } \\
\text { TODAS LAS } \\
\text { CIUDADES DE } \\
\text { ANDALUCía }\end{array}$ \\
\hline $\begin{array}{l}\text { No patentes registradas, } \\
\text { 2000-2008 }\end{array}$ & 13 & 71 & 120 & 25 & 11 \\
\hline $\begin{array}{l}\text { No patentes registradas 2000-2008 / } \\
\text { empresas totales 2008 (\%) }\end{array}$ & 0,50 & 1,54 & 0,94 & 0,68 & 0,77 \\
\hline No empresas exportadoras, 2008 & 25 & 88 & 93 & 29 & 33 \\
\hline $\begin{array}{l}\text { No empresas exportadoras / } \\
\text { empresas totales (\%), 2008 }\end{array}$ & 0,95 & 1,91 & 0,73 & 0,80 & 0,94 \\
\hline
\end{tabular}

FUENTE OFICINA ESPAÑOLA DE PATENTES Y MARCAS; INSTITUTO COMERCIO EXTERIOR 


\section{La capacidad innovadora de las empresas}

Tal y como se comentó anteriormente, el análisis de la innovación empresarial tiene ya una gran tradición en la literatura científica. Durante bastante tiempo se la identificó con la transmisión de conocimientos codificados y, por ello, fácilmente reproducibles, siendo de este modo susceptibles de intercambio o adquisición en el mercado. Se consideraba, además, que estaba relacionada con factores internos a la propia firma (Lundvall, 1999). Posteriormente, estableciendo la diferencia entre conocimiento codificado y tácito (Ancori, Bureth \& Cohendet, 2000), se desarrolló la tesis de que la innovación no es un fenómeno de carácter individual sino colectivo, y de que el medio o entorno en el que se desenvuelve la firma contribuye decisivamente a su promoción (Aydalot, 1986; Maillat, 1995; Méndez, 2002). Se puso, pues, el énfasis en el conocimiento tácito que, al no estar codificado, se transfiere a través de relaciones interpersonales que se producen fundamentalmente a escala local. Abundando en ello, Moulaert (2008) insiste en el carácter enraizado del conocimiento y en el protagonismo que con ello adquiere el territorio.

En relación con lo anterior, existe un acuerdo generalizado en que las empresas, y los territorios en los que estas se insertan, tienen que basar su desarrollo económico en la utilización del conocimiento, aunque no necesariamente en su generación, hecho este último que es especialmente importante en aquellos territorios en los que el tejido empresarial se caracteriza por el predominio de unidades productivas de tamaño pequeño o medio y por especializarse en sectores maduros no intensivos en conocimiento (Krüger, 2006). Es importante tener en cuenta que estos últimos rasgos son característicos de las ciudades objeto de estudio.

Para profundizar en el análisis de la capacidad innovadora de las empresas ha sido necesario realizar encuestas en las tres ciudades estudiadas ${ }^{4}$. En Alcalá de Guadaíra y Almería, los establecimientos empresariales que dicen haber realizado innovaciones representan más del 90 por ciento del total, mientras que su peso en Antequera no llega al 75 por ciento. Como puede observarse en el Gráfico 1, que sintetiza la información mediante la utilización de diagramas estrella, son más numerosas las innovaciones de proceso y de mercado, sobre todo en Alcalá de Guadaíra y Almería, mientras es más limitado el peso de las de producto, y solo destacan las de organización en Alcalá de Guadaíra. El comportamiento de Antequera resulta muy diferente, siendo significativas en esta ciudad las estrategias de diferenciación a partir de marcas o distintivos de calidad. Las innovaciones de carácter medioambiental tienen una cierta presencia en Almería.

Las encuestas se realizaron entre junio de 2008 y junio de 2009 a partir de un muestreo estratificado en el que los sectores seleccionados en las tres ciudades fueron los correspondientes a la industria y servicios intensivos en conocimiento. En el caso de Antequera, se añadió a los anteriores el comercio al por mayor, dada la especialización de esta ciudad en actividades logísticas y de distribución; y en el de Alcalá de Guadaíra, la industria extractiva, por su significación en el municipio. Las muestras fueron de 78 encuestas en Antequera, 82 en Alcalá de Guadaíra y 85 en Almería, con un nivel de confianza del 95 por ciento y un margen de error del 10 por ciento. 
GráfICo 1 | Tipos de innovaciones realizadas por los establecimientos empresariales (porcentajes)
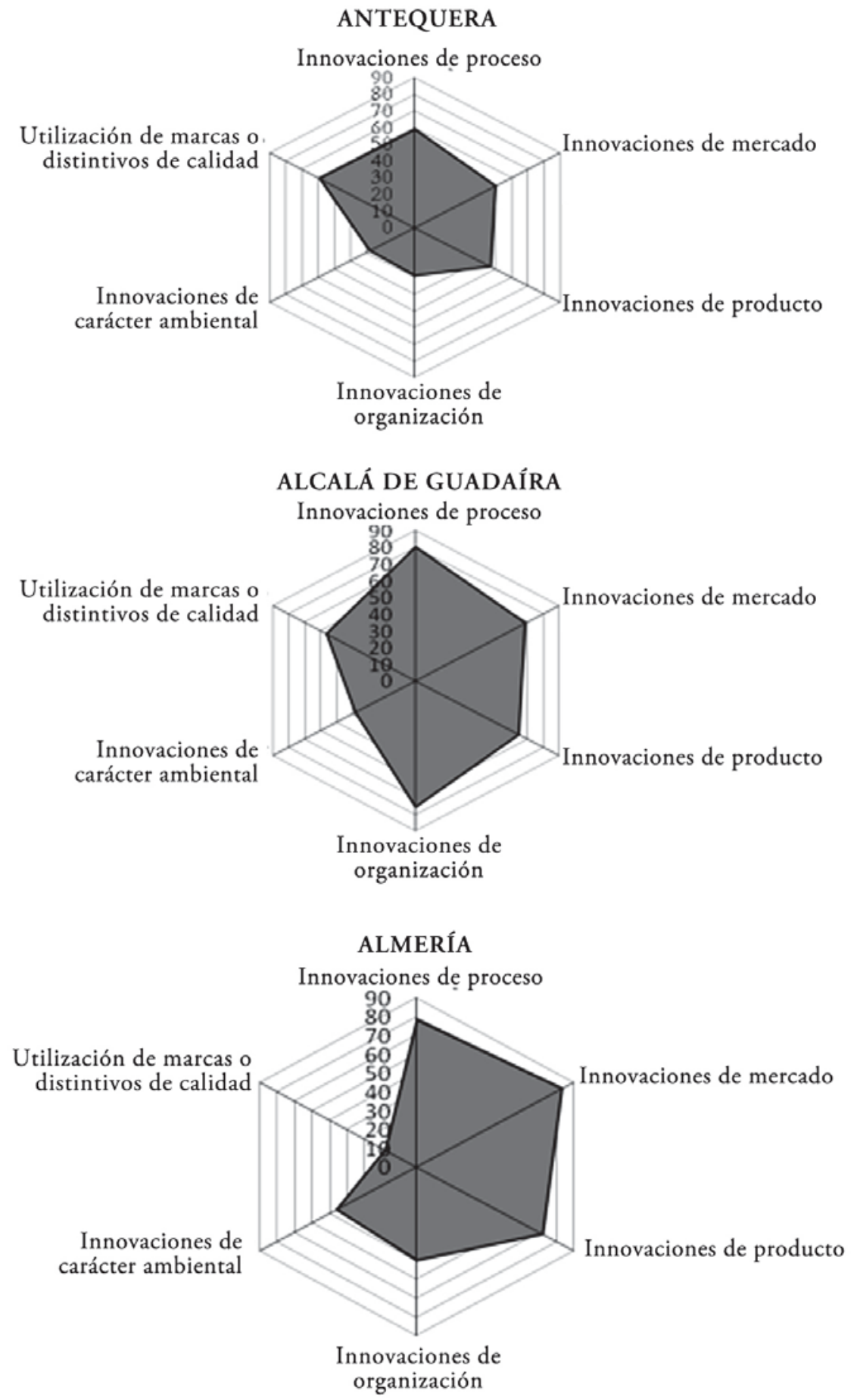

FUENTE ENCUESTAS 
Pero, tal como se señaló anteriormente, la capacidad innovadora de las empresas está en buena medida condicionada por el llamado aprendizaje colectivo, por lo que las relaciones de colaboración con otras firmas e instituciones son de crucial importancia para la transmisión del conocimiento tácito. Como muestra el Cuadro 5, los establecimientos empresariales encuestados en Antequera y Almería dicen mantener un mayor número de relaciones de colaboración con otras empresas, siendo por el contrario estos vínculos menos frecuentes en Alcalá de Guadaíra; no obstante, es en esta última ciudad donde las empresas que colaboran entre sí (17 por ciento del total) lo hacen en un mayor número de tareas. En las tres ciudades estudiadas, el porcentaje de las relaciones establecidas con administraciones, organismos o instituciones supera con mucho a las que se mantienen con otras empresas.

CUADRO 5 | Relaciones de colaboración establecidas por las empresas (porcentajes)

\begin{tabular}{|l|c|c|c|}
\cline { 2 - 4 } \multicolumn{1}{c|}{} & ANTEQUERA & $\begin{array}{c}\text { ALCALÁ DE } \\
\text { GUADAírA }\end{array}$ & ALMERÍA \\
\hline Con otras empresas & 28 & 17 & 29 \\
\hline Para comercializar & 15 & 43 & 40 \\
\hline Para formación de los trabajadores & 13 & 29 & 32 \\
\hline Para incorporación de innovaciones & 9 & 21 & 12 \\
\hline Para compra de materias primas & 8 & 43 & 24 \\
\hline Para asistencia a ferias & 4 & 43 & 20 \\
\hline Para utilización conjunta de maquinaria & 1 & 7 & 4 \\
\hline Para contratar técnicos & 1 & 14 & 8 \\
\hline Con administraciones, organismos o instituciones & 55 & 28 & 73 \\
\hline
\end{tabular}

FUENTE ENCUESTAS

\section{Las redes socio-institucionales de cooperación}

Junto a la innovación empresarial, cobra cada vez más importancia aquella vinculada a las actuaciones de otros agentes socioeconómicos e institucionales, ya sean estos privados o públicos. Estos agentes están condicionados en mayor o menor medida por los contextos territoriales, las estructuras socioeconómicas heredadas y la presencia de aquellos recursos que configuran su capital endógeno. Las capacidades y estrategias para la puesta en valor de tales recursos varían en cada territorio, como consecuencia de dinámicas socioeconómicas propias que constituyen una clave explicativa de la creación y mantenimiento, en su caso, de su posible ventaja competitiva. Ello implica que la caracterización de un territorio innovador debe incluir, junto a las diversas formas de innovación empresarial antes consideradas, las relacionadas con la llamada innovación social, que se vinculan con la cooperación entre las distintas instituciones y agentes con competencias en el territorio para impulsar procesos de innovación. De este modo, si, por una parte, la concepción reticular y relacional de los territorios refuerza el papel de las ciudades medias, por otra, las 
redes socio-institucionales locales de cooperación contribuyen a su desarrollo y a su inserción en la sociedad del conocimiento.

El interés que despierta la innovación social se observa también en la literatura científica de los últimos veinte años, de modo que se ha convertido en una referencia fundamental en los análisis sobre desarrollo y sobre los procesos de gobernanza a distintas escalas (Moulaert, Martinelli, Swyngedow \& González, 2005). Se insiste, pues, en la importancia de las redes locales de cooperación, entendiendo que favorecen y estimulan los procesos de aprendizaje colectivo e innovación. Tal y como señala Salom (2003), se trata de un nuevo paradigma relacional o asociativo "que sostiene que la existencia de relaciones y redes sociales de conocimiento mutuo, es un elemento decisivo en el éxito de los territorios" (p. 15).

Cuando se habla de redes socio-institucionales, se puede estar haciendo referencia a multitud de organizaciones con finalidades, formas de articulación y estructuras muy dispares. Interesan aquí especialmente las de cooperación para la promoción de la innovación y el desarrollo. Para que este tipo de redes sea verdaderamente efectivo, hay que tener en cuenta que los actores que se relacionan deben compartir objetivos comunes bien definidos que motiven el desarrollo de proyectos colectivos.

El estudio específico de las redes en las ciudades consideradas ha requerido un sistemático trabajo de campo en el que, mediante entrevistas en profundidad ${ }^{5}$, se han identificado los actores con presencia activa en cada una de ellas (Cuadro 6) y las intervenciones que realizan.

Pero, tan interesante como observar la profusión y variedad de agentes implicados en los procesos de dinamización económica y, en su caso, en la promoción de la innovación, es comprobar en qué medida los proyectos y actuaciones que pueden favorecer la inserción de las ciudades en la sociedad del conocimiento se derivan de la existencia de redes de cooperación entre agentes socio-institucionales. La mayor o menor articulación y cohesión interna de una red, medida en términos del número de relaciones que la conforman, resulta ilustrativa del grado de maduración que esta ha alcanzado, a la vez que puede ser determinante para la comunicación y difusión de información entre los actores, el crecimiento del capital social, la creación de entorno y el desarrollo del gobierno relacional.

La Figura 2 sintetiza a través de sociogramas el tejido de relaciones que, con objeto de llevar a cabo determinados proyectos, se establecen entre los actores con una presencia activa en los espacios estudiados. Como se puede observar en los gráficos, son las administraciones públicas las que establecen un mayor número de relaciones, con un peso considerable de la administración local en las ciudades de menor tamaño (Alcalá de Guadaíra y Antequera); por su parte, la administración regional adquiere mayor significado en la de Almería, en donde también tienen un peso significativo las asociaciones empresariales. En cuanto a la densidad de relaciones ${ }^{6}$, la ciudad que cuenta con una trama más compleja es Alcalá de Guadaíra (con

5 Se ha realizado un total de 57 entrevistas semiestructuradas entre 2009 y 2011: 22 en Antequera, 14 en Alcalá de Guadaíra y 21 en Almería.

6 La densidad de las relaciones indica el número de vínculos directos (A) existentes en la red respecto al máximo que podría tener en el caso de que todos y cada uno de los actores $(\mathrm{N})$ estuvieran relacionados directamente entre sí. La fórmula es $2 \mathrm{~A} / \mathrm{N}(\mathrm{N}-1)$. 
un índice de conectividad del 61 por ciento), seguida de Almería (cuyo índice es del 53 por ciento), siendo de menor relevancia la conformada en Antequera (donde el valor del índice es del 44 por ciento).

CUADRO 6 | Agentes socio-institucionales con presencia activa en las ciudades estudiadas

\begin{tabular}{|c|c|c|}
\hline ANTEQUERA & ALCALÁ DE GUADAÍRA & ALMERÍA \\
\hline \multicolumn{3}{|c|}{ Administraciones públicas } \\
\hline $\begin{array}{l}\text { - Ayuntamiento } \\
\text { - Diputación de Málaga } \\
\text { - Junta de Andalucía }\end{array}$ & $\begin{array}{l}\text { - Ayuntamiento } \\
\text { - Diputación de Sevilla } \\
\text { - Junta de Andalucía }\end{array}$ & $\begin{array}{l}\text { - Ayuntamiento } \\
\text { - Diputación de Almería } \\
\text { - Junta de Andalucía }\end{array}$ \\
\hline \multicolumn{3}{|c|}{ Organismos e infraestructuras de promoción económica } \\
\hline $\begin{array}{l}\text { - Organismo Autónomo para la } \\
\text { Promoción y el Desarrollo } \\
\text { - Grupo Acción Local Comarca } \\
\text { Antequera } \\
\text { - Unidad Comarcal de } \\
\text { Dinamización del Empleo } \\
\text { - Sociedad para la Promoción } \\
\text { y Explotación de los Recursos } \\
\text { de Antequera y su Comarca } \\
\text { - Unidad Territorial de Empleo y } \\
\text { Desarrollo Local y Tecnológico }\end{array}$ & $\begin{array}{l}\text { - Agencia Municipal de Desa- } \\
\text { rrollo } \\
\text { - Vivero de empresas } \\
\text { - Unidad Territorial de Empleo } \\
\text { y Desarrollo Local y Tecno- } \\
\text { lógico }\end{array}$ & $\begin{array}{l}\text { - Centro de Apoyo al Desarrollo } \\
\text { Empresarial de Almería } \\
\text { - Incubadora de empresas }\end{array}$ \\
\hline \multicolumn{3}{|c|}{ Organismos e infraestructuras de apoyo a la innovación } \\
\hline $\begin{array}{l}\text { - Red Espacios Tecnológicos de } \\
\text { Andalucía }\end{array}$ & $\begin{array}{l}\text { - Sociedad Innovar en Alcalá } \\
\text { - Fundación Alcalá Innova } \\
\text { - Centro de Realidad Virtual } \\
\text { - Incubadora de empresas de } \\
\text { base tecnológica } \\
\text { - Centro de Apoyo a la Calidad } \\
\text { y la Seguridad en la Industria } \\
\text { - Red Espacios Tecnológicos de } \\
\text { Andalucía }\end{array}$ & $\begin{array}{l}\text { - Fundación Cajamar } \\
\text { - Fundación para la Investigación } \\
\text { Agraria, provincia de Almería } \\
\text { - Fundación Tecnova: Centro } \\
\text { Tecnológico de la Industria } \\
\text { Auxiliar de la Agricultura } \\
\text { - Fundación Universidad de } \\
\text { Almería (UAL)-Anecoop: Centro } \\
\text { de Innovación y Tecnología } \\
\text { - Parque Científico Tecnológico } \\
\text { de Almería } \\
\text { - Red Espacios Tecnológicos de } \\
\text { Andalucía }\end{array}$ \\
\hline \multicolumn{3}{|c|}{ Centros de formación } \\
\hline $\begin{array}{l}\text { Escuela de Empresas, Fundación } \\
\text { Andalucía Emprende }\end{array}$ & $\begin{array}{l}\text { - Instituto Tecnológico de } \\
\text { Formación } \\
\text { - Centro Formación Avanzada } \\
\text { - Universidad Pablo de Olavide }\end{array}$ & - Universidad de Almería \\
\hline
\end{tabular}


(continuación)

\begin{tabular}{|c|c|c|}
\hline ANTEQUERA & ALCALÁ DE GUADAÍRA & ALMERÍA \\
\hline \multicolumn{3}{|c|}{ Organizaciones y asociaciones empresariales. Sindicatos } \\
\hline $\begin{array}{l}\text { - Asociaciones empresariales: } \\
\text { Comerciantes e Industriales, } \\
\text { Iniciativas Turísticas de } \\
\text { Antequera, Turismo Sur de El } \\
\text { Torcal y Comunidad de } \\
\text { Propietarios Polígono Industrial } \\
\text { - Sindicatos }\end{array}$ & $\begin{array}{l}\text { - Cámara de Comercio } \\
\text { (Antena Cameral de Alcalá } \\
\text { de Guadaíra) } \\
\text { - Federación de Industriales y } \\
\text { Comerciantes de Alcalá de } \\
\text { Guadaíra } \\
\text { - Sindicatos }\end{array}$ & $\begin{array}{l}\text { - Cámara de Comercio } \\
\text { - ASEmpal (Confederación } \\
\text { Empresarial de la Provincia de } \\
\text { Almería), coeXPHAL (Asocia- } \\
\text { ción Provincial de Empresarios } \\
\text { Cosecheros Exportadores de } \\
\text { Productos Hortícolas de Al- } \\
\text { mería), EcoHAl (Asociación de } \\
\text { Empresarios Comercializadores } \\
\text { Hortofrutícolas de Almería), } \\
\text { APAL (Asociación Provincial } \\
\text { de Agrupaciones Agrarias de } \\
\text { Almería), AProA (Asociación de } \\
\text { Productores de Frutas y } \\
\text { Hortalizas de Andalucía) } \\
\text { - Federación Andaluza de Empresas } \\
\text { Cooperativas de Trabajo } \\
\text { - Sindicatos }\end{array}$ \\
\hline \multicolumn{3}{|c|}{ Organizaciones y asociaciones sociales } \\
\hline $\begin{array}{l}\text { - Plataforma Antequera Habitable } \\
\text { y Sostenible } \\
\text { - Federación de Asociaciones de } \\
\text { Vecinos }\end{array}$ & $\begin{array}{l}\text { - Plataforma Voluntariado So- } \\
\text { cial de Alcalá de Guadaíra } \\
\text { - Plataforma Salvemos el Guadaíra } \\
\text { - Grupo ecologista Alwadi-ira } \\
\text { - Federación de Asociaciones de } \\
\text { Vecinos }\end{array}$ & $\begin{array}{l}\text { - Foro Ciudad } \\
\text { - Foro Social } \\
\text { - Asociación vecinos La Traíńa } \\
\text { - Federación de Asociaciones de } \\
\text { Vecinos Argar } \\
\text { - Federación de Asociaciones de } \\
\text { Vecinos Espejo del Mar }\end{array}$ \\
\hline
\end{tabular}

FUENTE ENTREVISTAS

Si importantes son las redes de colaboración de carácter local, no menos interesantes son las establecidas con otros espacios, dado que, por una parte, pueden servir de canal de acceso y transferencia de conocimientos; y, por otra, parecen responder a las nuevas estrategias de gobierno del territorio (Castañer et al., 2009). Las tres ciudades objeto de estudio están integradas en redes externas y, aunque no se ha podido obtener información detallada sobre los efectos que estas ejercen en las mismas, sí parece interesante señalar al menos cuáles son: Red para el Desarrollo Turístico de las Ciudades Medias del Centro de Andalucía (Antequera), Red Andaluza de Desarrollo Estratégico Urbano y Territorial (Antequera y Alcalá de Guadaíra), Red Nacional de Ciudades de la Ciencia y la Innovación (Alcalá de Guadaíra), Red Española de Ciudades por el Clima (Almería), y Red Internacional de Ciudades Educadoras (Alcalá de Guadaíra y Almería). 
FIgURA 2 | Redes locales de cooperación socio-institucional, 2009

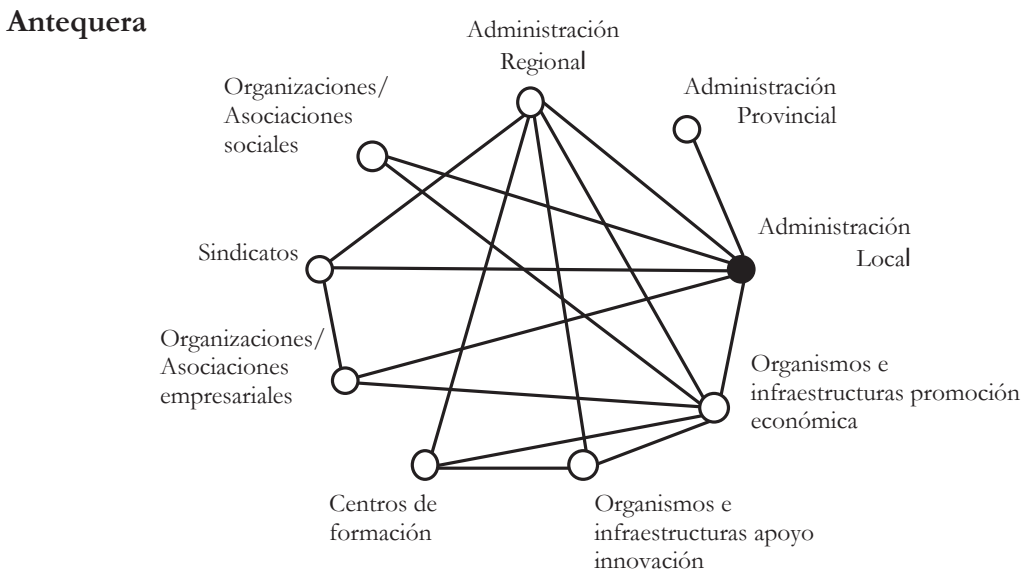

Alcalá de Guadaíra

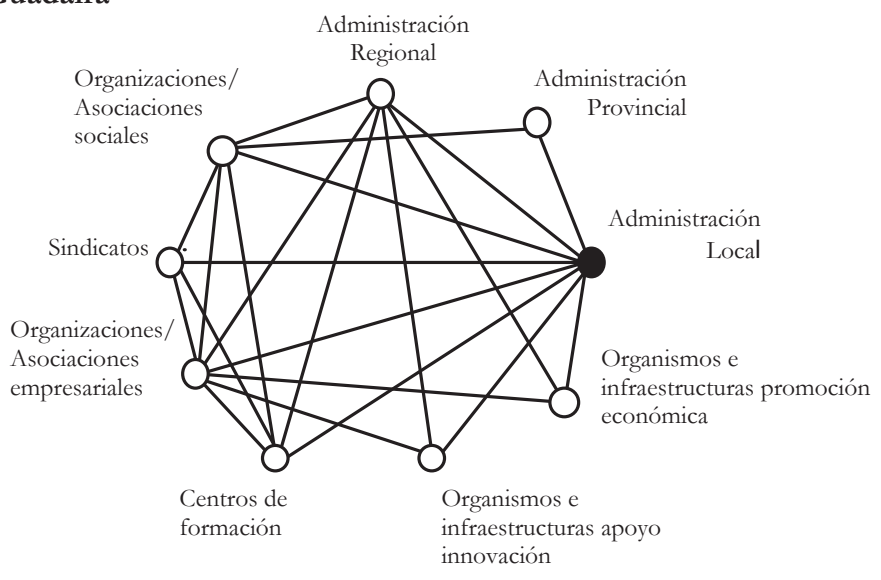

Almería

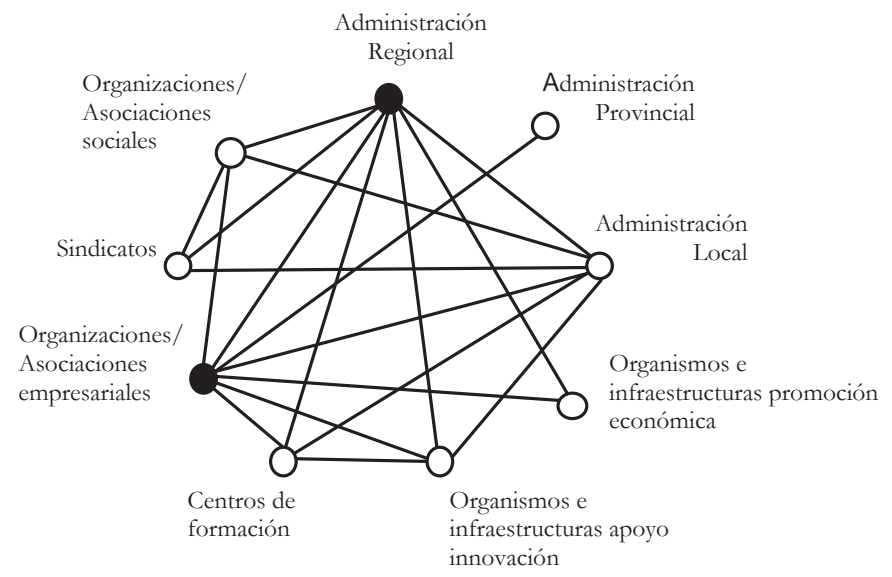

FUENTE ENTREVISTAS 


\section{Las estrategias públicas de desarrollo}

La construcción de ciudades intermedias innovadoras capaces de actuar como difusoras del conocimiento, la innovación y, en definitiva, el desarrollo a todo el territorio debe asociarse a la puesta en valor y la gestión inteligente de sus recursos. Para ello resulta necesario adoptar "nuevas formas de gobernanza territorial caracterizadas por la participación, la coordinación, la cooperación y la concertación" (Farinós \& Romero, 2007 , p. 16). Tales formas de gobernanza se asocian "al capital social territorial, por un lado, al fortalecimiento y la coordinación institucional, por otro, y, en definitiva, a la búsqueda de una nueva gobernabilidad territorial capaz de responder adecuadamente a los desafíos planteados por el contexto actual" (Méndez et al., 2006, p. 378).

En este sentido, adquieren un especial interés las estrategias que las instituciones locales llevan a cabo para avanzar en la construcción de un determinado proyecto de ciudad, lo que puede determinar el modo en que se integran en la sociedad del conocimiento.

Partiendo de tales premisas, un primer aspecto que considerar en el análisis que aquí se presenta es la existencia o no de un proyecto, más o menos consensuado, sobre el desarrollo futuro de las ciudades. En este sentido, resulta bastante ilustrativo que mientras Antequera y Alcalá de Guadaíra cuentan con su propio proyecto, en Almería predomina la opinión -contrastada a través del trabajo de campo y las entrevistas realizadas- de que la ciudad no tiene proyecto en el que sustentar las medidas y actuaciones que, según parece, poco coordinadas y muy aisladamente se están llevando a cabo. Pero no se trata únicamente de si se cuenta o no con un proyecto de ciudad, sino de analizar, entre otras cosas, el grado de innovación de las acciones llevadas a cabo en cuanto a la gestión de los recursos territoriales, al establecimiento de redes de colaboración entre los agentes socio-institucionales o a las actitudes y prácticas más o menos activas de estos. Al respecto, existe una primera diferencia sustancial entre las tres ciudades objeto de estudio: Almería no solo no ha realizado ningún plan estratégico, sino que, además, su Plan General de Ordenación Urbana está paralizado desde 2007 y se ha demorado en exceso el proceso de elaboración de la Agenda 21 Local, con la consiguiente pérdida de las subvenciones que apoyan este último tipo de actuaciones.

Considerando la falta de proyectos consensuados, no es de extrañar que las actuaciones que se están llevando a cabo en Almería sean puntuales y descoordinadas. El crecimiento económico experimentado por la provincia desde hace más de tres decenios no está apoyado por buenas infraestructuras de transporte, que siguen siendo insuficientes, e incluso la ciudad de Almería sigue estando muy mal conectada tanto por vía férrea como aérea, mientras que el puerto, que tuvo una importante actividad durante el siglo xIx y la primera mitad del xx, lleva tiempo sumido en una grave crisis. Junto a lo anterior, el hecho de que la base económica de la ciudad se sustente en actividades agrocomerciales y turísticas localizadas en municipios cercanos, ayuda a entender que Almería, pese a su condición de capital provincial, se esté quedando algo rezagada respecto al dinamismo socioeconómico de otras ciudades de su entorno más próximo, tal y como se indicaba en páginas anteriores. Esta crisis ayuda a entender que el proceso de crecimiento urbano de la ciudad haya sido 
desordenado y contradictorio, experimentando el centro histórico una grave degradación, con todo lo que ello implica tanto en relación con su despoblamiento como con la pérdida o el deterioro de bienes patrimoniales. Estos desórdenes estructurales pueden deberse a una falta de reflexión sobre el modelo urbano y a la consiguiente ausencia de un proyecto de ciudad. En este contexto, los foros ciudadanos están debatiendo sobre posibles estrategias de desarrollo que permitan sacar la ciudad de su atonía, mientras algunos agentes locales, tanto públicos como privados, están llevando a cabo ciertas actuaciones aisladas, entre las que resulta quizá la más básica la aprobación de un proyecto de regeneración integral del centro histórico dentro de la iniciativa Urban de la Unión Europea. A ello se une la creación del Parque de Innovación y Tecnología de Almería, que acogerá preferentemente empresas relacionadas con las energías renovables, la arquitectura bioclimática y el medioambiente.

Aunque las otras dos ciudades estudiadas (Antequera y Alcalá de Guadaíra) cuentan con planes estratégicos, sus situaciones son muy distintas en relación con las propuestas recogidas en cada uno de ellos.

Por lo que respecta a Antequera, la ciudad está afectada por dos planes estratégicos que no solo están liderados por actores diferentes, sino que carecen de vinculación alguna entre sí, sea en su concepción o en su proceso de elaboración. Uno ha sido promovido por el Grupo de Acción y Desarrollo Local Comarca de Antequera y el otro por el Ayuntamiento. Más interesante resulta el segundo plan que, con horizonte en 2016, parte de la consideración de la posición estratégica de este municipio en el centro de la región y del papel que, derivado de dicha posición, debe ejercer la ciudad; en relación con lo anterior, se identifican como sectores prioritarios el logístico y de distribución, además del cultural y el turístico, dedicándose una atención prioritaria a las infraestructuras de transportes. Así, junto a la llegada del tren de alta velocidad que, con el objeto explicitado de reducir costes, ha supuesto la construcción de una nueva estación alejada del núcleo urbano, se plantea una serie de proyectos, entre los que cabe destacar: un puerto seco, un aeropuerto comercial de carácter privado, una autopista de peaje que unirá la ciudad con la zona de clara vocación turística que es la Costa del Sol, y una llamada Zona Especial Turística, que contará con equipamientos y alojamientos, aunque en ella se limita el uso residencial. Esta lógica es asumida por un buen número de agentes socio-institucionales locales, que consideran imprescindibles estas grandes infraestructuras como base para la apuesta por la especialización de la ciudad en funciones de distribución.

Frente al grupo de agentes señalado, se sitúa otro colectivo social que se muestra muy crítico con tales estrategias, al considerar los posibles impactos negativos, tanto ambientales y paisajísticos como socioeconómicos, que las infraestructuras planificadas pueden generar en buena parte del territorio municipal, así como en las actividades agrarias e incluso turísticas. Entienden, así, que la implementación de todas las infraestructuras propuestas podría dar lugar a un modelo de crecimiento poco equilibrado y agresivo, que puede reducir las ventajas de una ciudad de tamaño medio con recursos ambientales, paisajísticos y culturales de gran valor, afectando con ello negativamente la calidad de vida de sus habitantes. Es decir, se pone en cuestión la forma en que se propone utilizar importantes recursos territoriales y patrimoniales existentes en este municipio. 
Por último, en Alcalá de Guadaíra, el Plan Estratégico 1998-2008 se planteaba como objetivo convertirla en una ciudad inteligente sustentada sobre tres pilares: la innovación empresarial, la educación como base del conocimiento, y la responsabilidad social. Tras una positiva valoración de dicho Plan por parte de los ciudadanos (92 por ciento, según la evaluación externa realizada por la empresa Deloitte), se prepara ahora un nuevo Plan Estratégico con horizonte en el año 2018. Entre las estrategias que lo sustentan destacan aquellas dirigidas a impulsar la innovación, para lo que se ha creado el Complejo de Innovación y Desarrollo de Alcalá de Guadaíra, donde se lleva a cabo una serie de actuaciones en colaboración con las administraciones regional y provincial, así como con otros organismos de carácter privado o mixto (Cuadro 6). Destaca fundamentalmente la Sociedad Innovar en Alcalá, de capital municipal, que, además de gestionar el Complejo, se encarga de asesorar y tutelar a las empresas, de promocionar suelo empresarial a precios más bajos que los del mercado, y de sensibilizar a los empresarios sobre la importancia de la innovación y el establecimiento de relaciones interempresariales. Junto a ella, la Fundación Alcalá Innova, de carácter mixto, lleva a cabo diversas actuaciones, entre las que cabe citar los convenios de colaboración suscritos con la administración regional para crear el Centro de Apoyo a la Calidad y la Seguridad en la Industria, cuyo objetivo es asesorar a las empresas en esta materia, y el Centro de Realidad Virtual, uno de los pocos públicos existentes en Espańa, que permite desde crear prototipos hasta realizar simulaciones de intervenciones quirúrgicas.

Especial mención merecen aquellas otras estrategias dirigidas a promover el conocimiento y a sensibilizar y responsabilizar a los habitantes en el proceso de construcción de ciudad. En cuanto a las primeras, se ha creado el Instituto Tecnológico de Formación, que organiza cursos y seminarios para empresarios y trabajadores; especial mención merece el Proyecto de Movilización Social Educativa Alcalá Educa que, además de contar con una línea de sensibilización de la cultura emprendedora, pretende reducir el fracaso escolar, educar en valores y fomentar el interés por el aprendizaje; en esta línea, se explica su integración en la Red Internacional de Ciudades Educadoras ya mencionada anteriormente. Respecto a las estrategias vinculadas a la sensibilización social, se está llevando a cabo, en colaboración con la Organización Internacional del Trabajo, el Proyecto Territorio Socialmente Responsable, cuyo objetivo es implicar a la sociedad local en un proyecto de ciudad económicamente dinámica, ambientalmente sostenible y socialmente cohesionada; en él participan asociaciones empresariales y sociales, empresas, sindicatos, universidades y la administración regional.

\section{Conclusiones}

El conocimiento y la innovación cobran un creciente protagonismo en los procesos de desarrollo territorial, al condicionar la forma en que se aprovechan los recursos, así como el modo en que se insertan los territorios en el espacio global y en la llamada sociedad del conocimiento. A su vez, aumenta la atención despertada por aquellas ciudades medias que pueden ser capaces de actuar como intermediadoras entre las de mayor tamańo y los ámbitos rurales, contribuyendo con ello al equilibrio y al 
desarrollo territorial. Reviste, pues, especial interés el análisis del comportamiento de estas ciudades medias, enfocado en su capacidad para innovar, la forma en que utilizan sus recursos y su grado de inserción en la sociedad del conocimiento.

En relación con los indicadores disponibles en España, una vez más, se han evidenciado sus insuficiencias para valorar a escala local la capacidad innovadora de los territorios, por lo que ha sido de gran utilidad el uso de información complementaria de carácter cualitativo.

Según evidencia buena parte de los indicadores relacionados con la innovación y el conocimiento, las tres ciudades objeto de esta investigación destacan entre las que conforman el sistema urbano andaluz, aunque se comportan de forma diferenciada, pudiéndose valorar más positivamente la situación de Alcalá de Guadaíra y de Almería, mientras el comportamiento de Antequera es menos favorable. Esta primera consideración debe, sin embargo, matizarse teniendo en cuenta la localización y las características de cada una de ellas; así, su condición de ciudad perteneciente a un área metropolitana, en el caso de Alcalá de Guadaíra, y de capital administrativa provincial, en el de Almería, pueden contribuir a explicar su posición por encima de los valores medios alcanzados en su conjunto por las ciudades clasificadas como medias, según su volumen poblacional.

Igual ocurre si se analiza la capacidad innovadora de las empresas, más significativa en Alcalá de Guadaíra y Almería, mientras que las relaciones de colaboración que se establecen entre firmas y entre estas y otros agentes socio-institucionales están más presentes en Antequera y Almería. Pese a ello, es precisamente en Alcalá de Guadaíra donde la red local de colaboración entre agentes públicos y privados es más potente. Esto último está estrechamente relacionado con las estrategias llevadas a cabo por las instituciones y los proyectos de ciudad que en cada una de las estudiadas se están realizando. De este modo, mientras que las actuaciones llevadas a cabo en Almería parecen en cierta medida desconectadas y no existe una propuesta clara para el desarrollo futuro de la ciudad, en Antequera se está optando por un modelo económico y urbano sustentado en la construcción de potentes infraestructuras de transporte que, en buena parte de los casos, afectan negativamente a bienes patrimoniales especialmente valiosos. Mucho más interesantes son las estrategias desarrolladas por el ayuntamiento de Alcalá de Guadaíra, muy directamente encaminadas a potenciar la innovación empresarial y el interés de la sociedad por el aprendizaje, lo que le puede permitir a esta ciudad no solo una mejor inserción en la sociedad del conocimiento, sino también una mayor calidad de vida para sus habitantes y, en consecuencia, un efectivo proceso de desarrollo territorial.

Para incorporarse a la sociedad del conocimiento y avanzar hacia un desarrollo integrado, resultan necesarias actitudes innovadoras que posibiliten la puesta en valor de los recursos y la asunción colectiva de un proyecto de ciudad. Esto cobra especial interés en las ciudades medias, puesto que, además de profundizar en su propio desarrollo, deben actuar como intermediadoras entre las grandes ciudades y los espacios rurales. Para ello -y más aún en contextos como el andaluz, aquejados de importantes debilidades estructurales- es fundamental que los poderes públicos sean del nivel administrativo que sean, aunque de forma especial los 
de carácter local, establezcan los mecanismos necesarios para favorecer tanto la cohesión social como la territorial en sus ámbitos de gestión. A tal fin, deben promover los comportamientos solidarios propios de territorios inteligentes, que son aquellos que contribuyen a mejorar la calidad de vida y el bienestar de todos sus habitantes. OEURE

\section{Referencias bibliográficas}

Albertos, J. M.; Caravaca, I.; Méndez, R. \& Sánchez, J. L. (2004). Desarrollo territorial y procesos de innovación socioeconómica en sistemas productivos locales. En J. L. Alonso, J. Aparicio \& J. L. Sánchez (Eds.), Recursos territoriales y geografía de la innovación industrial en España (pp. 15-60). Salamanca: Ediciones Universidad de Salamanca.

Amin, A. \& Cohendet, P. (2004). Architectures of knowledge: Firms, capabilities, and communities. Oxford: Oxford University Press.

Ancori, B.; Breth, A. \& Cohendet, P. (2000). The economics of knowledge: The debate about codification and tacit knowledge. Industrial and corporate change, 9(2), 42-60. doi: $10.1093 / \mathrm{icc} / 9.2 .255$

Arboníes, A. (2005). Una propuesta conceptual sobre nuevos indicadores para la ciudad del conocimiento. Ekonomiaz, 59, 233-245. Disponible en http://www1.euskadi.net/ekonomiaz/indice_c.apl

Atkinson, R. (2001). The emerging urban agenda and the European spatial development perspective: Towards a Eu urban policy? European Planning Studies, 9(3), 385-406. doi: $10.1080 / 713666487$

Aydalot, P. (1986). Milieux innovateurs en Europe. París: Groupe de recherche européen sur les milieux innovateurs (GREMI).

Balbo, M. (1997). Ciudades intermedias y gestión urbana en Europa. Santiago de Chile: Comisión Económica para América Latina y el Caribe (Cepal).

Bellet, C. \& Llop, J. M. (2000). Ciudades intermedias, urbanización y sostenibilidad. Lleida: Ed. Milano.

Boisier, S. (2001, septiembre). Sociedad del conocimiento, conocimiento social y gestión territorial. Interaçoes. Revista Internacional de Desenvolvimiento Local, 2(3), 9-28. Disponible en http://site.ucdb.br/public/downloads/9079-vol-2-n-3-set-2001.pdf

Brugué, Q.; Gomá, R. \& Subirats, J. (2002). Introducción. En J. Subirats (Coord.), Redes, territorios y gobierno. Nuevas respuestas locales a los retos de la globalización (pp. 17-24). Barcelona: Universidad Internacional Menéndez Pelayo (UIMP).

Caravaca, I.; García, A. \& González, G. (2012). Hacia la integración de Andalucía en la sociedad del conocimiento. Algunas estrategias públicas regionales, metropolitanas y locales. Ciudad y Territorio. Estudios Territoriales, 44(172), 263-280.

Caravaca, I.; González, G. \& Mendoza, A. (2007). Indicadores de dinamismo, innovación y desarrollo. Su aplicación en ciudades pequeñas y medias de Andalucía. Boletín de la AGE, 43, 131-154. Disponible en http://www.boletinage.com/ 
Caravaca, I.; González, G.; Mendoza, A. \& Silva, R. (2009). Dinamismo, innovación y desarrollo en ciudades pequeñas y medias de Andalucía. Sevilla: Consejo Económico y Social. Disponible en http://www.juntadeandalucia.es/servicios/publicaciones/detalle/75874. html

Carnoy, M. \& Castells, M. (2001). Globalization, the knowledge society, and the Network State: Poulantzas at the millennium. Global Networks, 1, 1-18. doi: 10.1111/14710374.00002

Carrillo, J. C. (Ed.). (2006). Knowledge Cities. Approaches, Experiences and Perspectives. Oxford: Elsevier.

Castañer, M.; Ganau, J.; Hass, C.; Heras, M.; Llusà, R.; Mallarach, J., (...) \& Rovira, T. (2009). Las redes de ciudades: gobiernos emergentes en las ciudades intermedias catalanas. En I. Caravaca, V. Fernández Salinas \& R. Silva (Coords.), Ciudades, culturas y fronteras en un mundo en cambio (pp. 56-66). Sevilla: Consejería de Obras Públicas y Transportes, Junta de Andalucía. Disponible en http://infodigital.opandalucia.es/ bvial/handle/10326/256

Cating, M.; Lacour, C. \& Lung, Y. (2001). Introduction. Revue d'Economie Régionale et Urbaine, 1, 3-20. Disponible en http://www.cairn.info/revue-d-economie-regionale-eturbaine-2001-1-page-3.htm

Coe, N. M. (2005). Putting knowledge in its place. A review essay. Journal of Economic Geography, 5(3), 381-384. doi:10.1093/jnlecg/lbh047

Cooke, P. (2002). Knowledge economies. Clusters, learning and cooperative advantage. Londres: Routledge.

David, P. A. \& Foray, D. (2002). An introduction to the Economy of the Knowledge Society. International Science Journal, 54(171), 9-23. doi: 10.1111/1468-2451.00355

Davoudi, S. (2003). Polycentricity in European spatial planning: From an analytical tool to a normative Agenda. European Planning Studies, 11(8), 979-999. doi: $10.1080 / 0965431032000146169$

Drucker, P. F. (1969). The age of discontinuity: Guidelines to our changing society. Nueva York: Harper \& Row.

Farinós, X. \& Romero, J. (Eds.). (2007). Territorialidad y buen gobierno para el desarrollo sostenible. Nuevos principios y nuevas politicas en el espacio europeo. Valencia: Universidad de Valencia.

Feldman, M. P. (1994). The geography of innovation. Dordrecht: Kluwer Academic Publisher.

Fernández Macho, J. \& González Casimiro, P. (2009). Evaluación de territorios inteligentes en la sociedad del conocimiento. La Coruña: Netbiblo, S.L.

García García, A. (2008). El dinamismo socioeconómico de Andalucía. Territorios ganadores y territorios emergentes. Sevilla: Universidad de Sevilla, Secretariado de Publicaciones. Disponible en http://grupo.us.es/giest/sites/default/files/IDTA3_Monogrqafia_1

Gaspar, J. (2000). Cidades médias e cidades intermédias. Novas funçôes territoriais e novas formas urbanas em Portugal. En C. Bellet \& J. M. Llop (Eds). Ciudades intermedias, urbanización y sostenibilidad (pp. 35-62). Lleida: Ed. Milenio.

González, G. (2006). Innovación, redes y territorio en Andalucía. Sevilla: Universidad de Sevilla y Consejería de Obras Públicas y Transportes, Junta de Andalucía. 
González Romero, G. (2009). Modelos territoriales de innovación en Andalucía. Sevilla: Universidad de Sevilla Secretariado de Publicaciones. Disponible en http:/grupo.us.es/giest/ sites/default/files/IDTA3_Monogrqafia_2

Henderson, V. (1997). Medium-size cities. Regional Science and Urban Economics, 27(6), 583612. doi: 10.1016/S0166-0462(96)02169-2

Krüger, K. (2006). El concepto de la "sociedad del conocimiento". Biblio 3W. Revista Bibliográfica de Geografía y Ciencias Sociales (Serie documental de Geo Crítica), 11(683). Disponible en http://www.ub.edu/geocrit/bw-ig.htm

Lundvall, B. A. (1999). La base del conocimiento y su producción. Ekonomiaz, Revista Vasca de Economía, 45, 14-37. Disponible en http://www1.euskadi.net/ekonomiaz/taula4_c. apl?REG $=567$

Machlup, F. (1962). The production and distribution of knowledge in the United States. Princeton, NJ: Princeton University Press.

Maillat, D. (1995). Les milieux innovateurs. Sciences Humaines, 8, 41-42.

Mackinnon, D.; Cumbers, A. \& Chapman, D. (2002). Learning, innovation and regional development: A critical appraisal of recent debates. Progress in Human Geography, 26(3), 293-311. doi: 10.1191/0309132502ph371 ra

Méndez, R. (2002). Innovación y desarrollo territorial: Algunos debates teóricos recientes. EURE, 28(84), 63-84. Disponible en http://www.eure.cl/numero/innovacion-ydesarrollo-territorial-algunos-debates-teoricos-recientes/

Méndez, R. (2009). Conocimiento e innovación para el desarrollo de ciudades intermedias. En I. Caravaca, V. Fernández Salinas \& R. Silva (Coords.), Ciudades, culturas y fronteras en un mundo en cambio (pp. 20-44). Sevilla: Consejería de Obras Públicas y Transportes, Junta de Andalucía. Disponible en http://infodigital.opandalucia.es/bvial/handle/10326/256

Méndez, R.; Abad, L.; Caravaca, I. \& González, G. (2010). Las ciudades de Andalucía ante la sociedad del conocimiento. Scripta Nova. Revista Electrónica de Geografía y Ciencias Sociales, 14(345). Recurso online. Disponible en http://www.ub.es/geocrit/sn/sn-345. htm

Méndez, R.; Michelini, J. J. \& Romeiro, P. (2006). Redes socio-institucionales e innovación para el desarrollo de las ciudades intermedias. Ciudad y Territorio, Estudios Territoriales, 38(148), 377-395. Disponible en http://bit.ly/12Lgc5X

Méndez, R.; Sánchez, S.; Abad, L. \& García, I. (2009). Sistema urbano y sociedad del conocimiento: hacia una tipología de las ciudades españolas. Investigaciones Regionales, 16, 117-142. Disponible en http://www.aecr.org/images/ImatgesArticles/2009/05\%20 Mendez.pdf

Moulaert, F. (2008). Innovación social. Institucionalmente enraizada, territorialmente (re)producida. En J. M. Albertos, J. Noguera, M. D. Pitarch \& J. Salom (Coords.), Globalización económica: amenazas y oportunidades para los territorios (pp. 9-17). Valencia: Grupo de Geografía Económica. Asociación de Geógrafos Españoles y Universidad de Valencia.

Moulaert, F.; Martinelli, F.; Swyngedow, E. \& González, J. (2005). Towards alternative model(s) of local innovation. Urban Studies, 42, 1969-1990. doi: 10.1080/00420980500279893 
Moulaert, F. \& Nussbaumer, M. (2005). The social region. Beyond the territorial dynamics of the learning economy. European Urban and Regional Studies, 12(1), 45-64. doi: $10.1177 / 0969776405048500$

Moulaert, F. \& Sekia, F. (2003). Territorial innovation models: A critical survey. Regional Studies, 37(3), 289-302. doi:10.1080/0034340032000065442

O’Huallacháin, B. \& Leslie, T. F. (2007). Rethinking the regional knowledge production function. Journal of Economic Geography, 7(6), 737-752. doi: 10.1093/jeg/lbm027

Pita, M. F. \& Pedregal, B. (Coords.). (2011). Tercer Informe de Desarrollo Territorial de Andalucia. IDTA 2010. Sevilla: Universidad de Sevilla, Agencia de Innovación y Desarrollo de Andalucía. Disponible en http://grupo.us.es/node/801

Rohrbach, D. (2007). The development of knowledge societies in 19 OECD countries between 1970 and 2002. Social Science Information, 46(4), 655-689. doi: $10.1177 / 0539018407082596$

Romeiro, P. \& Méndez, R. (2008, agosto). Las ciudades del conocimiento: revisión crítica y posibilidades de aplicación a las ciudades intermedias. Scripta Nova Revista Electrónica de Geografía y Ciencias Sociales 12(270). Número especial. X Coloquio Internacional de Geocrítica. Disponible en http://www.ub.edu/geocrit/sn/sn-270/sn-270-50.htm

Rooney, D.; Hearn, G.; Mandeville, T. \& Joseph, R. (2003).: Public policy in knowledge-based economies: Foundations and frameworks. Cheltenham: Edward Elgar.

Salom, J. (2003). Innovación y actores locales en los nuevos espacios económicos: un estado de la cuestión. Boletín de la Asociación de Geógrafos Españoles, 36, 7-30. Disponible en http://www.boletinage.com/36/3601.pdf

Simmie, J.; Sennett, J.; Wood, P. \& Hart, D. (2002). Introduction: The knowledge-based city. Urban Studies, 39(5-6), 855-857. doi: 10.1080/00420980220128336

Winden, W.; Van Berg, L. \& Pol, P. (2007). European cities in the knowledge economy: towards a typology. Urban Studies, 44(3), 525-549. doi: 10.1080/00420980601131886

Zoido, F. (Coord.). (2001). Primer Informe de Desarrollo Territorial de Andalucía. Sevilla: Universidad de Sevilla, Fundación Sevillana de Electricidad, La General.

Zoido, F. \& Caravaca, I. (Coords.). (2005). Segundo Informe de Desarrollo Territorial de Andalucía. Sevilla: Universidad de Sevilla.

\section{Documentos oficiales}

European Commission. (1999). European Spatial Development Perspective. Towards balanced and sustainable development of the territory of the European Union. Luxemburgo: Office for Official Publications of the European Communities. Disponible en http://ec.europa. eu/regional_policy/sources/docoffic/official/reports/pdf/sum_en.pdf

European Commission. (2005). Methodology report on European innovation scoreboard 2005, Innovation and SME programme. Luxemburgo: Office for Official Publications of the European Communities.

European Commission. (2006). European innovation scoreboard 2006. Comparative analysis of Innovation performance. Masstricht: MERIT (Maastricht Economic Research Institute on Innovation and Technology), Joint Research Centre (Institute for the Protection and Security of the Citizen) of the European Commission. Disponible en http://www. berlin-partner.de/fileadmin/chefredaktion/pdf/studien-rankings/2006_en_EuropeanInnovation-Scoreboard.pdf 
Instituto de Estadística y Cartografía de Andalucía. (2011). Padrón municipal de habitantes [s.n]. Sevilla: Instituto de Estadística y Cartografía de Andalucía. Disponible en http:// www.juntadeandalucia.es/institutodeestadisticaycartografia/iea/consultasActividad. jsp?CodOper $=6 \&$ sub $=35298$

OCDE - Organización para la Cooperación y el Desarrollo Económicos. (2001). Cities and regions in the new learning economy. París: OECD. doi: 10.1787/9789264189713-en

Unesco - United Nations Educational, Scientific and Cultural Organization. (2005) Toward knowledge societies. París: Unesco. Disponible en http://unesdoc.unesco.org/ images/0014/001418/141843e.pdf 